In 2009, we completed an audit with colleagues at North Derbyshire Mental Health Services NHS Trust. The results illustrated that physical examination on admission to an inpatient unit increased from 67 to $83 \%$ by the end of the audit cycle. The reasons for not examining patients varied from 'transferred from medical ward' to 'team to review tomorrow'. We encouraged the consultant-led teams to take more responsibility in ensuring that a complete physical examination (including investigations such as baseline bloods and electrocardiograms) is done for every patient admitted to the unit, and also recommended quick and easy access to physical health equipment, especially out of hours.

While I appreciate the emphasis of the Royal College of Psychiatrists on increasing the awareness of physical illnesses in our client group and the importance of their detection, I believe actions speak louder than words. Our underperformance in this area is due to problems at multiple levels. Training in psychiatry has become completely detached from medicine. We need to increase psychiatric trainees' exposure to medicine by incorporating physical examination in the MRCPsych curriculum nationally and possibly offering a compulsory rotation in medicine during core training. We also need to change the ethos within psychiatric teams (in-patient and community based) by encouraging psychiatric nurses to also improve their medical skills.

It can be quite tricky in out-patients to address physical health problems while also managing mental health issues. Like other services, why can't we have a dedicated nurse at the outpatient clinic who records blood pressure, measures height, weight, hip and waist circumference, and does all the routine blood tests for every patient, before they go in to see the doctor?

1 Gonzalez C, Ahammed N, Fisher R. Improving physical health monitoring for out-patients on antipsychotic medication. Psychiatr Bull 2010; 34: 91-4.

2 Garden, G. Physical examination in psychiatric practice. Adv Psychiatr Treat 2005; 11: 142-9.

3 Harris EC, Barraclough B. Excess mortality of mental disorder. $\mathrm{Br} J$ Psychiatry 1998; 173: 11-53.

Yasir Abbasi, ST5, North Trent Psychiatric Rotation, Crisis Resolution and Home Treatment, Bassetlaw Hospital, Worksop, UK, email: dryiabbasi@yahoo.com

doi: $10.1192 / \mathrm{pb} .34 .5 .210$

\section{Attitudes to ECT - a nebulous concept with important implications}

Kinnair et al raise some important points regarding training and teaching students on electroconvulsive therapy (ECT). Some of the questions used, particularly in assessing students' attitudes to ECT, have been used in similar studies ${ }^{2,3}$ and would therefore carry some face validity. Clearly, it is important to consider the sequence of teaching events in any instructional design of a teaching block; however, I would disagree with some of the authors' conclusions. With such a descriptive study design, the use of binary variables (yes/no answers) and the absence of $P$-values, one cannot infer any significant differences between Groups A, B, C and D with regard to changes in knowledge of ECT. The relatively smaller sample sizes of these groups compared with the baseline sample would make a Type I error more likely, that is any differences seen could be due to chance.

Intuitively, one would expect either Group B or C to do better with their follow-up knowledge questions, simply based on constructivist theory (i.e. building on previously attained knowledge). In Group B, a certain amount of knowledge will be acquired from simply watching an ECT procedure. The authors did not state how soon after the lecture and/or witnessed ECT event, students were asked to complete the questionnaire. One cannot therefore assume a limited benefit (in terms of knowledge obtained) from watching ECT before receiving a lecture, as this could equally be due to having the lecture closer to the questionnaire.

I find the absence of any tables to explain the results of their attitudes questions somewhat disappointing. Previous research in this area has shown that medical students' attitudes to ECT can be improved by receiving a didactic lecture on $\mathrm{ECT}^{4}{ }^{4}$ as well as observing an ECT application (either live or a pre-recorded video), ${ }^{5}$ so it is not surprising that Group $B$ showed improved attitudes on two of the questions compared with Group D. It would have been interesting to know how many of those students who had seen either One Flew over the Cuckoo's Nest or Beautiful Mind belonged to Groups A or D, which could explain the different response with regard to question 10 - 'I would agree to have ECT if I was depressed'.

Better knowledge of ECT, particularly self-perceived knowledge, does not necessarily imply better attitudes to ECT. ${ }^{6}$ If we want to attract more students to our profession, further research in this area is essential to help unveil some of the secrets behind students' negative perceptions, attitudes and prejudices with regard to ECT.

1 Kinnair D, Dawson S, Perera R. Electroconvulsive therapy: medical students' attitudes and knowledge. Psychiatrist 2010; 34: 54-7.

2 Clothier JL, Freeman T, Snow L. Medical student attitudes and knowledge about ECT. J ECT 2001; 17: 99-101.

3 Abbas M, Mashrai N, Mohanna M. Knowledge of and attitudes toward electroconvulsive therapy of medical students in the United kingdom, Egypt, and Iraq: a transcultural perspective. J ECT 2007; 23: 260-4.

4 Papakosta VM, Zervas IM, Pehlivanidis A, Papadimitriou GN, Papakostas YG. A survey of the attitudes of Greek medical students toward electroconvulsive therapy. J ECT 2005; 21: 162-4.

5 Warnell RL, Duk AD, Christison GW, Haviland MG. Teaching electroconvulsive therapy to medical students: effects of instructional method on knowledge and attitudes. Acad Psychiatry 2005; 29: 433-6.

6 Gazdag G, Kocsis-Ficzere N, Tolna J. Hungarian medical students' knowledge about and attitudes toward electroconvulsive therapy. J ECT 2005; 21: 96-9.

Schalk W. du Toit, Specialty Registrar, ST6 General Adult Psychiatry, NHS Grampian, Royal Cornhill Hospital, Aberdeen, UK, email: s_dutoit@doctors.org.uk

doi: $10.1192 / p b .34 .5 .211$

\section{Concerns over professional boundaries remain unresolved}

The Executive Committee of the Spirituality and Psychiatry Special Interest Group (SPSIG) of the Royal College of Psychiatrists has made a rather late response ${ }^{1}$ to Harold Koenig's editorial ${ }^{2}$ published in this journal in 2008. We were co-signatories to a letter ${ }^{3}$ that was highly critical of some of 